\title{
Contrasting the eastern Pacific El Niño and the central Pacific El Niño: process-based feedback attribution
}

\author{
Xiaoming $\mathrm{Hu}^{1} \cdot$ Song Yang $^{1} \cdot$ Ming $\mathrm{Cai}^{2}$
}

Received: 17 May 2015 / Accepted: 30 December 2015 / Published online: 9 January 2016

(C) The Author(s) 2016. This article is published with open access at Springerlink.com

\begin{abstract}
This paper examines the roles of radiative and non-radiative air-sea coupled thermodynamic processes in modifying sea surface temperature (SST) anomalies driven by (air-sea coupled) oceanic dynamic processes, focusing on their contributions to the key differences between the eastern Pacific (EP) El Niño and the central Pacific (CP) El Niño. The attribution is achieved by decomposing SST anomalies into partial temperature anomalies due to individual processes using a coupled atmosphere-surface climate feedback-response analysis method. Oceanic processes induce warming from the central to the eastern equatorial Pacific and cooling over the western basin with a maximum warming center in the central Pacific for both types of El Niño. The processes that act to oppose the oceanic process-induced SST anomalies are surface latent heat flux, sensible heat flux, cloud, and atmospheric dynamic feedbacks, referred to as negative-feedback processes. The cooling due to each of the four negative-feedback processes is the strongest in the region where the initial warming due to oceanic processes is the largest. Water-vapor feedback is the sole process that acts to enhance the initial warming induced by oceanic processes. The increase in atmospheric water vapor over the eastern Pacific is much stronger for the EP El Niño than for the CP El Niño. It is the strong watervapor feedback over the eastern Pacific and the strong negative feedbacks over the central equatorial Pacific that help
\end{abstract}

Song Yang

yangsong3@mail.sysu.edu.cn

1 School of Atmospheric Sciences and Institute of Earth Climate and Environment System, Sun Yat-sen University, 135 West Xingang Road, Guangzhou 510275, China

2 Department of Earth, Ocean, and Atmospheric Science, Florida State University, Tallahassee, FL, USA to relocate the maximum warming center from the central Pacific to the eastern basin for the EP El Niño.

Keywords El Niño $\cdot$ SST anomaly $\cdot$ Air-sea coupled thermodynamic process $\cdot$ Water-vapor feedback

\section{Introduction}

El Niño-Southern Oscillation (ENSO) is the leading mode of tropical air-sea interaction that influences weather and climate worldwide on a variety of time scales. According to the locations of warmest sea surface temperature (SST) anomalies, El Niño can be roughly divided into two types: eastern Pacific (EP) El Niño and central Pacific (CP) El Niño (Yu and Kao 2007; Kao and Yu 2009). The EP El Niño is the classical El Niño with the maximum warming in the eastern equatorial Pacific and has been subject to extensive studies (e.g., Bjerknes 1969; Rasmusson and Carpenter 1982; Neelin et al. 1998). The CP El Niño is featured with the maximum warming in the central equatorial Pacific and is also referred to as dateline El Niño (Larkin and Harrison 2005), or El Niño Modoki (Ashok et al. 2007), or warmpool El Niño (Kug et al. 2009). The EP type is close to the canonical ENSO event depicted by Rasmusson and Carpenter (1982), while the CP type shows new characteristics in terms of its spatial structure (Kao and Yu 2009; Kug et al. 2009; Wang and Wang 2013), underlying dynamic mechanisms (Vimont et al. 2001, 2003, 2009; Yu et al. 2010, 2015), and temporal evolution (e.g., Schneider et al. 1995; Ashok et al. 2007; Lee and McPhaden 2010). Moreover, the amplitude of the maximum warming center is larger for the EP El Niño than for the CP El Niño (Sun and Yu 2009).

With the differences in SST anomalies, the signals of the two types of El Niño in the atmosphere are different 
over the tropical Pacific. Pronounced westerly anomalies associated with the EP El Niño are found over the entire span of the tropical Pacific basin; but for the CP El Niño, the westerly anomalies exist mainly from the western to the central tropical Pacific, with a more westward location of the rising branch of the anomalous Walker Circulation (Ashok et al. 2007; Yuan and Yang 2012; Yuan et al. 2012). For the EP El Niño, increase in atmospheric water vapor and strong upward motion anomalies are found mainly over the central and eastern Pacific (Xie et al. 2012; Takahashi et al. 2013). However, maximum water-vapor increase and enhanced convective activity are located in the central Pacific for the CP El Niño (Xie et al. 2012; Takahashi et al. 2013). The centers of positive cloud anomalies are located in the central Pacific for both types of El Niño, but the EP type has a broader zonal scale (Zheng et al. 2014). The changes in surface wind and precipitation per changes in SST are greater for the CP El Niño than for the EP El Niño (Chung and Li 2013). Ozone concentration exhibits a more pronounced reduction in the stratosphere over the eastern tropical Pacific for the CP El Niño, compared to the EP type (Xie et al. 2014).

Previous studies have found that leading processes responsible for the ENSO include Bjerknes feedback (1969), the delay-oscillator mechanism (Suarez and Schopf 1988), the thermocline feedback associated with rechargedischarge processes (Jin 1997a, b), zonal advective feedback (Picaut et al. 1997), wind-evaporation-SST feedback. However, the relative importance of individual dynamic processes for the EP and CP type events is different. The development of EP El Niño exhibits a strong discharge of equatorial heat content and thermocline feedback in the formation of the pattern of SST anomalies (e.g., Jin and An 1999; Kug et al. 2009, 2010; Capotondi 2013, Capotondi et al. 2015; Lübbecke and McPhaden 2014). For the CP type, the zonal advection feedback is important (e.g., Kao and Yu 2009; Kug et al. 2009, 2010; Yu et al. 2010). The difference in the relative importance of (air-sea coupled) oceanic dynamic processes also explains the amplitude difference between the two types of El Niño (Zheng et al. 2014).

Besides the oceanic dynamic processes, air-sea coupled thermodynamic processes also play important roles in producing the spatial pattern and amplitude of SST anomalies associated with El Niño. air-sea heat fluxes, especially latent heat flux, have been found to have more important impacts on the SST anomalies over the central Pacific, compared to the SST anomalies over the eastern Pacific (e.g., Kao and Yu 2009; Kug et al. 2010). Cloud shortwave and latent heat feedbacks usually represent a local damping of SST anomalies (Lloyd et al. 2011, 2012). Water-vapor feedback acts to enhance SST anomalies (e.g., Chandra et al. 1998, 2007; Dessler and Wong 2009). The difference in radiative flux anomalies due to different cloud responses is also a key factor for the differences between the two types of El Niño. Attributions of other differences such as air temperature, water vapor and surface heat fluxes to the SST differences between the two types of El Niño have not been systematically studied.

Despite many studies that have been conducted to contrast oceanic dynamic processes between EP El Niño and CP El Niño based on heat budget using the SST equation (Kug et al. 2009, 2010), few studies have attempted to provide a quantitative comparison of air-sea coupled thermodynamic processes. The main objective of this study is to understand how the radiative and non-radiative thermodynamic feedbacks at the air-sea interface modify the SST anomalies driven by oceanic dynamic processes in contributing to the differences between the two types of El Niño over the equatorial Pacific basin. An off-line diagnostic approach named the Climate Feedback-Response Analysis Method (CFRAM; Cai and Lu 2009; Lu and Cai 2009) is applied to isolate partial SST changes due to individual radiative (e.g., changes in clouds, water vapor and air temperature) and non-radiative (surface sensible and latent heat fluxes) feedback processes. The CFRAM has been applied to quantify the contribution of dynamic process to polar warming amplification (Lu and Cai 2010), climate feedback attributions to seasonality of surface warming (Sejas et al. 2014), climate response to external forcing such as increases in carbon dioxide concentration and solar radiation (Cai and Tung 2012), radiative and dynamic forcing of temperature anomalies related to ENSO (Park et al. 2012; Deng et al. 2013), the northern annular mode (Deng et al. 2013), and model bias attributions (Park et al. 2013; Yang et al. 2014). As shown in Sect. 2, by the design of the method, our study does not attempt to further isolate individual oceanic dynamic processes, which can be done by decomposing the oceanic dynamic terms into local SST tendency, advective and upwelling terms in the SST equation (e.g., Kang et al. 2001; Kug et al. 2009, 2010).

The remaining of this paper is organized as follows. Section 2 presents the details of the data and formulation of CFRAM adopted in this study. Section 3 describes the differences in temperature and its associated atmospheric variables between the two types of El Niño. Section 4 focuses on the source of different surface temperature responses to the two types of El Niño over the central and eastern Pacific. Section 5 discusses the similarities and differences in various feedbacks during CP El Niño and EP El Niño. Conclusions are presented in Sect. 6.

\section{Data and CFRAM formulation}

Variables used in a complete feedback attribution analysis include skin temperature, air temperature, specific 
humidity, surface specific humidity, cloud amount, cloud liquid/ice water content, ozone mixing ratio, surface albedo, surface latent/sensible heat fluxes, and solar insolation at the top of the atmosphere. All input variables are obtained from the EAR-Interim (Uppala et al. 2008; Dee et al. 2011), which is the latest European Centre for Medium-range Weather Forecasts (ECMWF) global atmospheric reanalysis from 1979 to present. The ERA-Interim has 37 unevenly-divided pressure levels from 1000 to $1 \mathrm{hPa}$ and a horizontal resolution of $1.5^{\circ} \times 1.5^{\circ}$. We focus on the boreal winters from 1979 to 2012 because the CP El Niño was rarely observed before the 1980s (Kao and Yu 2009; Yeh et al. 2009).

Following Yu et al. (2012), we define CP El Niño and EP El Niño events based on the consensus of the EP/ CP index (Yu et al. 2012), the El Niño Modoki index (Ashok et al. 2007) and the Niño3/Niño4 index (Yeh et al. 2009). These definitions lead to a total off our winters $(1982 / 1983,1986 / 1987,1997 / 1998$, and 2006/2007) as major EP El Niño events and four winters (1994/1995, 2002/2003, 2004/2005, and 2009/2010) as major CP El Niño events in the period of 1979-2012 for constructing composite EP and $\mathrm{CP}$ events, respectively. In addition, we have identified a total of eight ENSO-neutral winters (1980/1981, 1981/1982, 1985/1986, 1989/1990, 1992/1993, 1993/1994, 2001/2002, and 2003/2004) for constructing composite neutral event. The fields derived from the differences between the composite EP and neutral events are referred to as the (composite) EP anomaly fields, whereas those from the differences between the composite $\mathrm{CP}$ and neutral events as the (composite) $\mathrm{CP}$ anomaly fields.

We use the CFRAM to account for the contributions to composite temperature anomalies of the two types of El Niño from individual feedback processes. Following Deng et al. (2012), we consider the difference in the energy balance equation between the two states,

$\Delta \frac{\partial \vec{E}}{\partial t}=\Delta(\vec{S}-\vec{R})+\Delta \vec{Q}$

where $\Delta$ denotes the differences between $\mathrm{CP}$ El Niño and ENSO-neutral events or between EP El Niño and ENSOneutral events. Specifically, $\Delta \frac{\partial \overrightarrow{\mathrm{E}}}{\partial \mathrm{t}}$ is the difference in energy storage between the two states; $\Delta \overrightarrow{\mathrm{S}}(\Delta \overrightarrow{\mathrm{R}})$ is the difference in vertical profiles of convergence (divergence) of shortwave (longwave) radiation flux within individual layers; and $\Delta \vec{Q}$ represents the difference in vertical profiles of energy flux convergence due to non-radiative dynamic processes. Evoking linear approximation, $\Delta(\overrightarrow{\mathrm{S}}-\overrightarrow{\mathrm{R}})$ can be decomposed into partial differences due to individual radiative feedback processes as follows:

$$
\begin{aligned}
& \Delta(\vec{S}-\vec{R}) \approx \Delta(\vec{S}-\vec{R})^{(w)}+\Delta(\vec{S}-\vec{R})^{(c)} \\
& +\Delta \vec{S}^{(\alpha)}+\Delta(\vec{S}-\vec{R})^{\left(O_{3}\right)}-\left(\frac{\partial \vec{R}}{\partial \vec{T}}\right) \Delta \vec{T}
\end{aligned}
$$

where the terms with superscripts " $w$ ", "c", " $\alpha$ " and "O $\mathrm{O}_{3}$ " correspond to, respectively, the partial radiative heating rate differences due to the differences in water vapor, clouds, albedo, and ozone between the two states. The last term in (2), i.e., the product of $\left(\frac{\partial \vec{R}}{\partial \vec{T}}\right)$ and $\Delta \vec{T}$, is the partial radiative cooling rate difference due to the difference in temperature between the two climate states in each atmospheric layer and at the surface (denoted as $\Delta \overrightarrow{\mathrm{T}})$ ). The matrix $\left(\frac{\partial \overrightarrow{\mathrm{R}}}{\partial \overrightarrow{\mathrm{T}}}\right)$ is called the Planck feedback matrix whose $j$ th column represents the vertical profile of changes in longwaver adiative energy flux due to $1 \mathrm{~K}$ warming in the $j$ th layer alone. Substituting (2) into (1) yields

$\Delta \vec{T}=\left(\frac{\partial \vec{R}}{\partial \vec{T}}\right)^{-1}\left\{\begin{array}{l}\left(\Delta \vec{S}^{(w)}-\Delta \vec{R}^{(w)}\right)+\left(\Delta \vec{S}^{(c)}-\Delta \vec{R}^{(c)}\right) \\ +\left(\Delta \vec{S}^{\left(O_{3}\right)}-\Delta \vec{R}^{\left(O_{3}\right)}\right)+\Delta \vec{S}^{(\alpha)}+\left(\Delta \vec{Q}-\Delta \frac{\partial \vec{E}}{\partial t}\right)\end{array}\right\}$

Applying the linear decomposition principle, we can calculate the following partial temperature changes separately,

$$
\left\{\begin{array}{l}
\Delta \vec{T}^{(w)}=\left(\frac{\partial \vec{R}}{\partial \vec{T}}\right)^{-1}\left(\Delta \vec{S}^{(w)}-\Delta \vec{R}^{(w)}\right) \\
\Delta \vec{T}^{(c)}=\left(\frac{\partial \vec{R}}{\partial \vec{T}}\right)^{-1}\left(\Delta \vec{S}^{(c)}-\Delta \vec{R}^{(c)}\right) \\
\Delta \vec{T}^{\left(O_{3}\right)}=\left(\frac{\partial \vec{R}}{\partial \vec{T}}\right)^{-1}\left(\Delta \vec{S}^{\left(O_{3}\right)}-\Delta \vec{R}^{\left(O_{3}\right)}\right) \\
\Delta \vec{T}^{(\alpha)}=\left(\frac{\partial \vec{R}}{\partial \vec{T}}\right)^{-1} \Delta \vec{S}^{(\alpha)} \\
\Delta \vec{T}^{(\text {non-radiative) }}=\left(\frac{\partial \vec{R}}{\partial \vec{T}}\right)^{-1}\left(\Delta \vec{Q}-\Delta \frac{\partial \vec{E}}{\partial t}\right)
\end{array}\right.
$$

The first four equations in (4) are ready to be solved since $\left(\frac{\partial \vec{R}}{\partial \vec{T}}\right)^{-1}$ and the partial radiative heating/cooling rate differences have already been obtained.

We further separate the term $\left(\Delta \vec{Q}-\Delta \frac{\partial \overrightarrow{\mathrm{E}}}{\partial \mathrm{t}}\right)$ into surface and atmospheric components. The surface component includes the perturbations of surface sensible heat $\left(\Delta \mathrm{Q}^{S H}\right)$ and latent heat $\left(\Delta \mathrm{Q}^{L H}\right)$ fluxes over both land and oceans, which can be obtained directly from the composite El Niño (EP or $\mathrm{CP}$ ) anomaly fields, and non-radiative heating perturbations due to oceanic energy transport convergence and the energy storage term $\left(\Delta \frac{\partial \mathrm{E}}{\partial \mathrm{t}}\right)$ at the surface, which are not available from the ERA-interim. We estimate the sum of oceanic dynamic and heat storage term as the residual of the surface energy balance equation, which is referred to as the oceanic process term and denoted as $\Delta \mathrm{Q}^{\text {ocean }}$,

$\Delta Q^{\text {ocean }}=-(\Delta S-\Delta R)_{\text {surf }}-\Delta Q^{L H}-\Delta Q^{S H}$ 
Similarly, we can estimate the sum of total non-radiative heating perturbations and the heat storage term in the atmospheric column as the residual of the atmospheric portion of (1), namely,

$\Delta \overrightarrow{\mathrm{Q}}^{\text {atmos }}=-(\Delta \overrightarrow{\mathrm{S}}-\Delta \overrightarrow{\mathrm{R}})_{\text {atmos }}$

where $(\Delta \overrightarrow{\mathrm{S}}-\Delta \overrightarrow{\mathrm{R}})_{\text {atmos }}$ is identical to $(\Delta \overrightarrow{\mathrm{S}}-\Delta \overrightarrow{\mathrm{R}})$ except that its surface component is set to zero. Note that $\Delta \overrightarrow{\mathrm{Q}}^{\text {atmos }}$ includes all forms of heating perturbations in the atmosphere such as atmospheric (vertical and horizontal) motions and the energy that goes into the atmosphere due to surface sensible and latent heat fluxes, as well as the atmospheric energy storage term. Because the energy storage term is very small after applying a long-term average (i.e., average of $4 \times 3$ months in this study), we simply refer to $\Delta \overrightarrow{\mathrm{Q}}^{\text {atmos }}$ as the atmospheric dynamics term.

Based on the discussion above, the term $\Delta \overrightarrow{\mathrm{T}}^{\text {(non-radiative) }}$ on the left hand side of the last equation in (4) can be obtained as the sum of the following partial temperature perturbations,

$\left\{\begin{array}{l}\Delta \vec{T}^{(S H)}=\left(\frac{\partial \vec{R}}{\partial \vec{T}}\right)^{-1} \Delta \vec{Q}^{S H} \\ \Delta \vec{T}^{(L H)}=\left(\frac{\partial \vec{R}}{\partial \vec{T}}\right)^{-1} \Delta \vec{Q}^{L H} \\ \Delta \vec{T}^{(\text {ocean })}=\left(\frac{\partial \vec{R}}{\partial \vec{T}}\right)^{-1} \Delta \vec{Q}^{\text {ocean }} \\ \Delta \vec{T}^{(\text {atmos })}=\left(\frac{\partial \vec{R}}{\partial \vec{T}}\right)^{-1} \Delta \vec{Q}^{\text {atmos }}\end{array}\right.$

where $\Delta \overrightarrow{\mathrm{Q}}^{S H}, \Delta \overrightarrow{\mathrm{Q}}^{L H}$, and $\Delta \overrightarrow{\mathrm{Q}}^{\text {ocean }}$ are zero in all atmospheric layers and equal to, respectively, $(\Delta \mathrm{S}-\Delta \mathrm{R})_{\text {surf }}-\Delta \mathrm{Q}^{L H}-\Delta \mathrm{Q}^{S H}$ at the surface. Solving (4) and (7) grid by grid enables us to obtain these partial temperature perturbations as a function of longitude, latitude and pressure. In the remaining of the paper, we focus on the surface components of these 3D partial temperature perturbation fields over the tropical Pacific $\left(30^{\circ} \mathrm{N}-30^{\circ} \mathrm{S}\right)$, and refer to them as partial SST anomalies (denoted as $\Delta \mathrm{T}$ ). Because the change in surface albedo over the tropics is negligible and the effect of perturbation in ozone concentration on temperature perturbation is of importance mainly in the stratosphere, we will only present the results of partial SST anomalies due to other six processes in the remaining of this paper.

We wish to add that the analysis of partial SST anomalies based on (4) and (7) is complementary to the heat budget analysis based on the SST equation (e.g., Hirst 1986; Wakata and Sarachik 1991; Kang et al. 2001; Kug et al. 2009). The term $\Delta \mathrm{T}^{(\text {ocean })}$ corresponds to the sum of the SST anomaly due to the ocean heat storage term and the convergence of energy transport by oceanic motions (e.g., anomalous vertical, zonal and meridional advections).
In reference to the conventional heat budget analysis based on the SST equation (e.g., Hirst 1986; Nagai et al. 1992; Kang et al. 2001), the heat storage term corresponds to the local SST tendency, and the convergence term corresponds to the sum of SST tendencies due to horizontal advective processes and upwelling/downwelling. By the design of our method, we cannot further decompose the oceanic dynamic term into local SST tendency, advective and upwelling terms in the SST equation.

Physically, the residual term in the SST equation corresponds to the SST anomalies due to air-sea coupled thermodynamic processes, including all other non-oceanic terms derived from (4) and (7). In this study, our focus is on the decomposition of contributions from these individual air-sea coupled thermodynamic processes to SST anomalies associated with the two types of El Niño, instead of the decomposition of the SST anomalies due to oceanic dynamic processes. As indicated in (4) and (7), the residual term in the SST equation is decomposed into partial SST anomalies due to surface latent heat flux anomalies $\left(\Delta \mathrm{T}^{(L H)}\right)$, surface sensible heat flux anomalies $\left(\Delta \mathrm{T}^{(S H)}\right)$, radiative flux anomalies associated with water-vapor feedback $\left(\Delta \mathrm{T}^{(w)}\right)$, radiative flux anomalies associated with cloud feedback $\left(\Delta \mathrm{T}^{(c)}\right)$, and thermal radiative flux anomalies associated with atmospheric dynamics-induced air temperature anomalies $\left(\Delta \mathrm{T}^{(a t m o s)}\right)$. This allows us to examine how the radiative and non-radiative thermodynamic feedbacks at the air-sea interface modify the SST anomalies driven by oceanic dynamic processes in contributing to the differences between the two types of ENSO over the equatorial Pacific basin.

\section{Observed anomalies of CP EI Niño and EP El Niño}

Figure $1 \mathrm{a}, \mathrm{b}$ show the observed December-January-February (DJF) mean SST anomalies of EP El Niño and CP El Niño, respectively. During the peak of EP El Niño, the center of positive SST anomalies extends from the coast of South America to the eastern equatorial Pacific; during the peak of CP El Niño, the center is located in the central Pacific with a relatively smaller magnitude. Overall, the spatial patterns of SST anomalies of both EP El Niño and CP El Niño are consistent with those shown in Larkin and Harrison (2005).

The column-integrated water-vapor anomalies of EP El Niño and CP El Niño (Fig. 2a, b) are positive over the equatorial central and eastern Pacific, more or less consistent with the SST anomalies. The column-integrated cloudcontent distributions (i.e., the sum of cloud liquid water and cloud ice water) of the two types of El Niño (Fig. 2c, d), however, exhibit latitudinal spatial pattern that are 

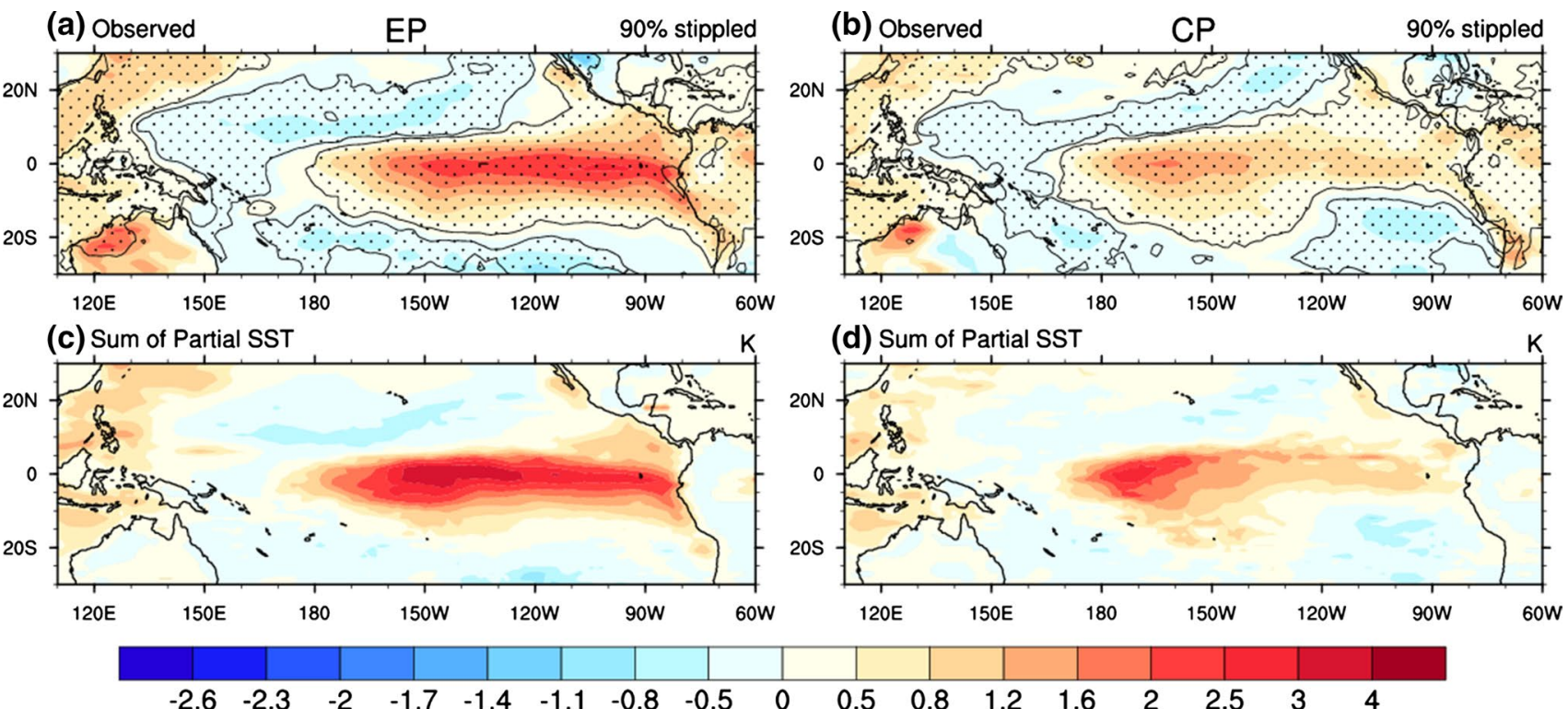

(d) Sum of Partial SST

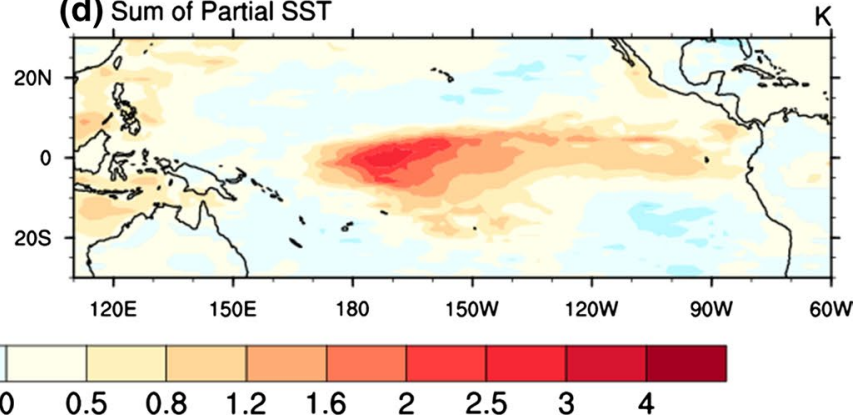

Fig. 1 DJF mean anomalies: observed SST anomalies $(\mathbf{a}, \mathbf{b})$ and sum of partial SST anomalies for EP (left panels) and CP (right panels) El Niño winters derived through the CFRAM at the surface (c, d). Stip- pling in $\mathbf{a}$ and $\mathbf{b}$ indicates the $90 \%$ confidence level of statistical significance. Units: K (a) Specific Humidity(EP)

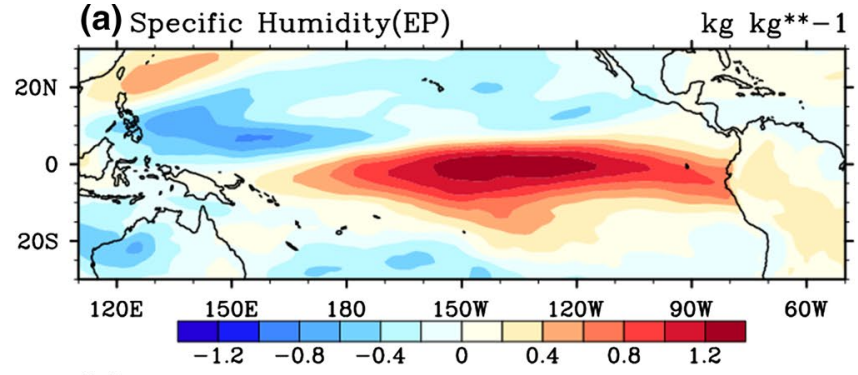

(c) Cloud Water(EP)

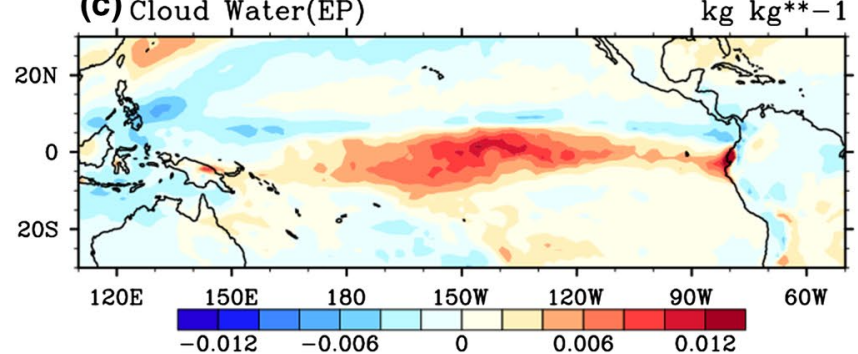

(e) $500 \mathrm{hPa}$ Vertical Velocity(EP)

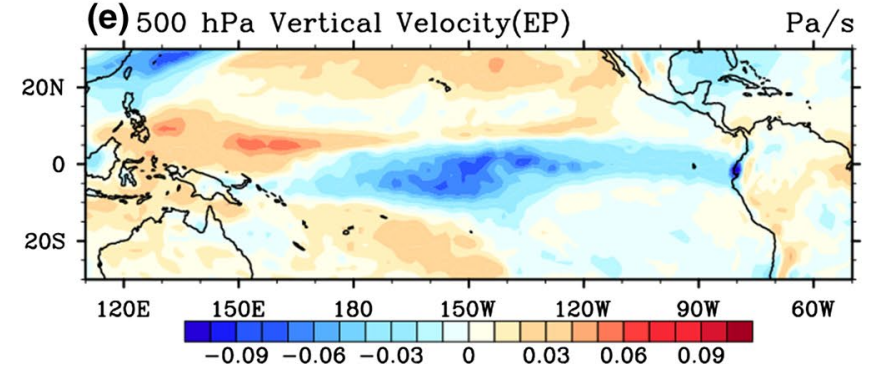

Fig. 2 DJF mean anomalies for column integral specific humidity $(\mathrm{kg} / \mathrm{kg})$ for EP El Niño (a) and CP El Niño (b). c, d are the same as (a) and (b), except for cloud water. Shown also are the composite pat- (b) Specific Humidity(CP)

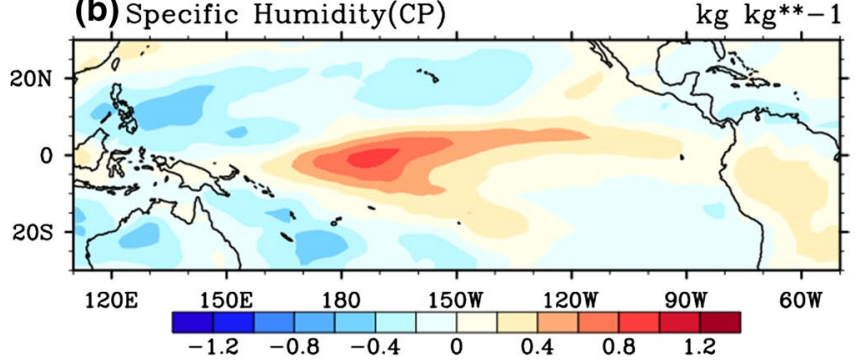

(d) Cloud Water(CP) $\quad \mathrm{kg} \mathrm{kg}^{* *-1}$
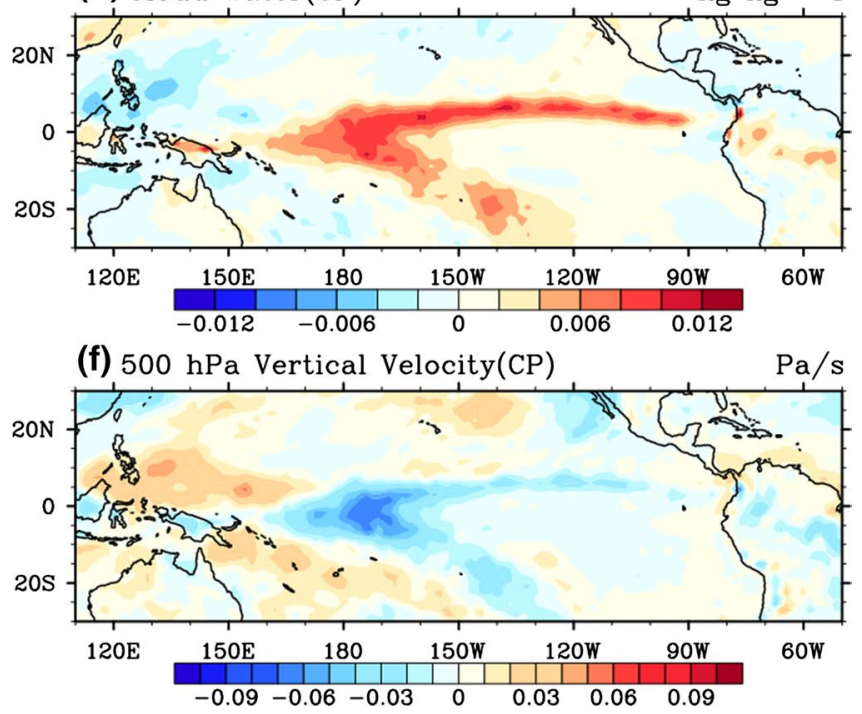

terns of vertical velocity anomalies at $500 \mathrm{hPa}$ for EP El Niño (e) and CP El Niño (f) 
distinctly different from the corresponding SST anomalies. Specifically, the equatorial maximum center of cloud content in each case is located over the west of the maximum positive SST anomaly center. To the east, the maximum cloud anomaly center is split into two off-equator bands with the one on the north extending eastward and the other on the south extending southeastward. Further west of the positive cloud-content anomalies, there is a center of reduction in clouds over the western equatorial basin. A similar spatial pattern is found in vertical velocity anomalies (Fig. 2e, f), showing rising motion anomalies coincided with an increasing in clouds and descending anomalies over the region of reduced clouds. Descending anomalies and decrease in clouds on the west, together with ascending anomalies and increase in clouds on the east, are indicative of a weakened Walker Circulation (Lau and Yang 2002) on the west of the maximum SST anomalies. The two off-equator bands of ascending anomalies and increase in clouds suggest a strengthening Inter-Tropical Convergence Zone (ITCZ) on the east of the maximum SST anomalies. The main difference between the two types of El Niño is that, for the EP El Niño, positive cloud and ascending anomalies have a wider meridional extent over the equatorial central Pacific, whereas, for the CP El Niño, the strengthening of the southern ITCZ appears stronger. The correspondence of the changes in cloud and vertical motion is consistent with the characteristics of precipitation for the two types of El Niño reported by Zheng et al. (2014).

\section{Attributions of SST anomalies over the tropical Pacific}

In this section, we focus on the contributions of individual feedback processes to the SST anomaly patterns of the two types of El Niño shown in Fig. 1a, b. To verify the decomposition of total SST anomalies by the CFRAM, we also show the sum of these partial SST anomalies (Fig. 1c, d). We can see that the partial SST anomalies do add up to the total SST anomalies reasonably well, which gives us confidence to carry out attribution analysis.

As expected, oceanic processes lead to positive SST anomalies over the central and eastern equatorial Pacific for both types of El Niño (Fig. 3a, b). Because oceanic processes are regarded as the root causes for the occurrence, development and maintenance of El Niño, we also refer to $\Delta \mathrm{T}^{\text {(ocean) }}$ as the initial warming in the following discussion. Accompanied by the positive SST anomalies, oceanic processes are also responsible for the cold SST anomalies over the western equatorial basin. Such cold-west and warmeast SST anomaly pattern is consistent with the divergence of oceanic heat transport over the western equatorial Pacific and the convergence over the central and eastern equatorial
Fig. 3 CFRAM-derived partial SST anomalies for the EP El Niño in the boreal winter due to oceanic process (a), latent heat flux (c), sensible heat flux (e), cloud (g), atmospheric dynamic (i), and water vapor (k) feedback processes at the surface. $\mathbf{b}, \mathbf{d}, \mathbf{f}, \mathbf{h}, \mathbf{j}, \mathbf{l}$ are the same as $\mathbf{a}, \mathbf{c}, \mathbf{e}, \mathbf{g}, \mathbf{i}$ and $\mathbf{k}$, except for the CP El Niño. Unit: $\mathrm{K}$

Pacific. For the CP El Niño, the maximum warming center of $\Delta \mathrm{T}^{\text {(ocean) }}$ seems to be co-located with the maximum center of the total SST anomalies, suggesting that the location of the maximum positive SST anomalies of CP El Niño can be largely explained by oceanic processes. The maximum warming center of $\Delta \mathrm{T}^{\text {(ocean) }}$ for the EP El Niño is also located over the central equatorial Pacific, slightly east of that for the CP type. This eastward shift during the EP El Niño is associated with the stronger thermocline feedback (Kug et al. 2009, 2010), which tends to be more effective in the eastern Pacific (Jin and An 1999). However, the location of maximum positive center of total SST anomalies of EP El Niño, which is over the eastern equatorial Pacific, cannot be explained by oceanic processes alone. It is of importance to note that the amplitudes of $\Delta \mathrm{T}^{\text {(ocean })}$ of both types of El Niño are greater than those of the actual SST anomalies by a factor of $5-10$. Other processes must act to suppress the oceanic process-induced SST anomalies substantially. Comparison of Fig. 3a with Fig. 1a suggests that, for the EP El Niño, other processes not only act to suppress the oceanic process-induced SST anomalies but also collectively play a role in determining the location of the maximum SST anomalies. For the CP El Niño, the other processes mainly act to suppress the oceanic process-induced SST anomalies.

Figure $3 \mathrm{c}-\mathrm{j}$ illustrate that all other processes, except the water-vapor feedback, act collectively to suppress the SST anomalies induced by oceanic processes. Of the two surface processes, the surface latent heat flux feedback (Fig. 3c, d) is the main contributor to the reduction of the positive SST anomalies over the central and eastern equatorial Pacific via strengthening surface evaporation or an increase in upward latent heat flux (not shown). Over the western basin, the surface latent heat flux feedback also acts to reduce the cold anomalies of $\Delta \mathrm{T}^{(\mathrm{ocean})}$ by reducing surface evaporation. Although not shown here, we confirm that there is an increase (a decrease) in the surface sensible heat flux over the regions where initial warming is positive (negative). Therefore, the surface sensible flux feedback plays a similar role, namely, reducing the initial warming over the central and eastern equatorial Pacific and reducing the initial cooling over the western equatorial Pacific. The reduction of initial warming by the surface sensible heat flux feedback is smaller than that by the evaporation feedback.

In terms of atmospheric processes, the cloud feedback (Fig. $3 \mathrm{~g}, \mathrm{~h}$ ) is the leading factor that suppresses the initial warming induced by oceanic processes. The increase in 


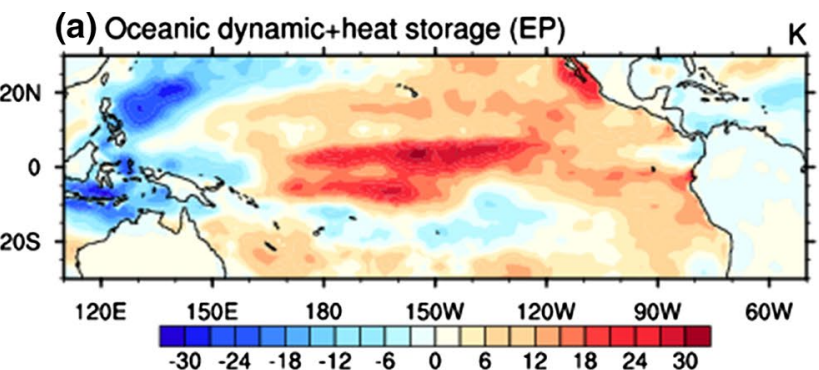

(c) Latent Heat Flux (EP)

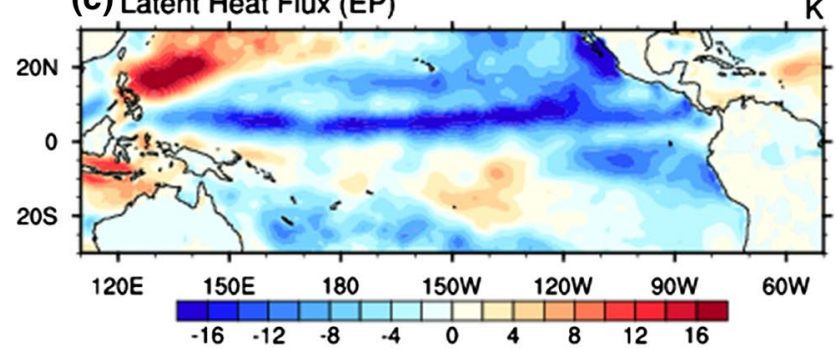

(e) Sensible Heat Flux (EP)

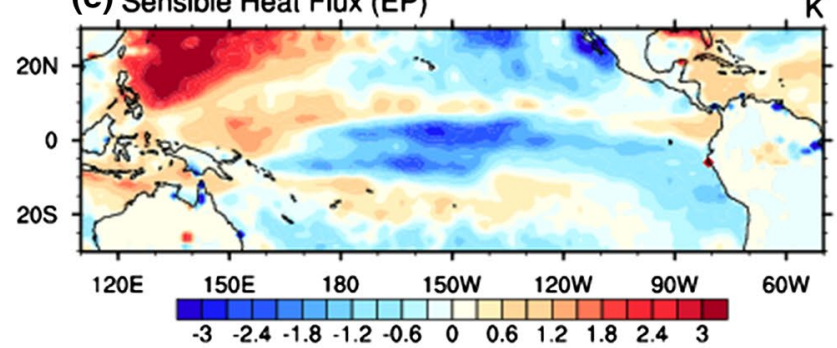

(g) Cloud (EP)

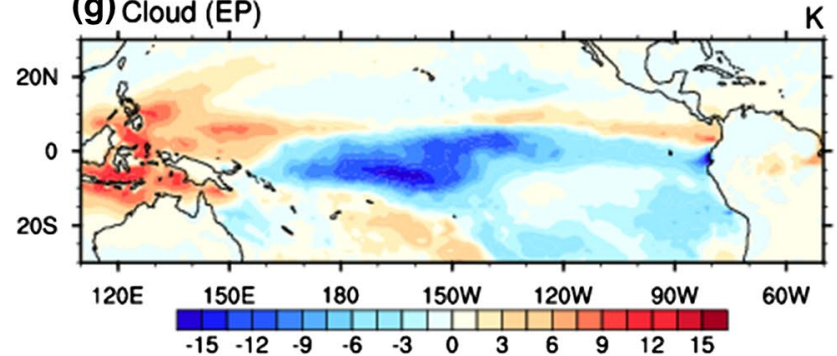

(i) Atmospheric Dynamic (EP)

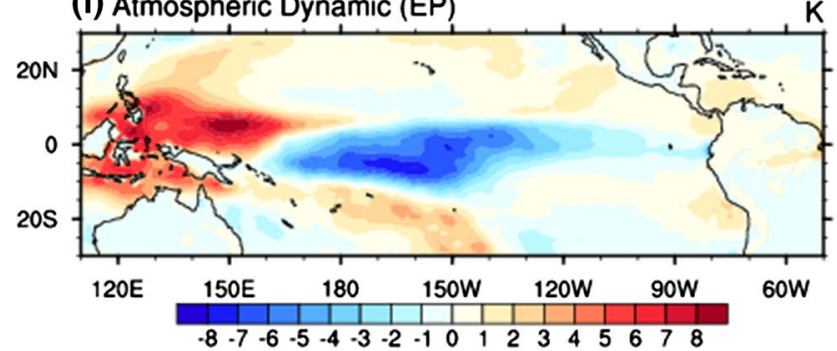

(k) Water Vapor (EP)

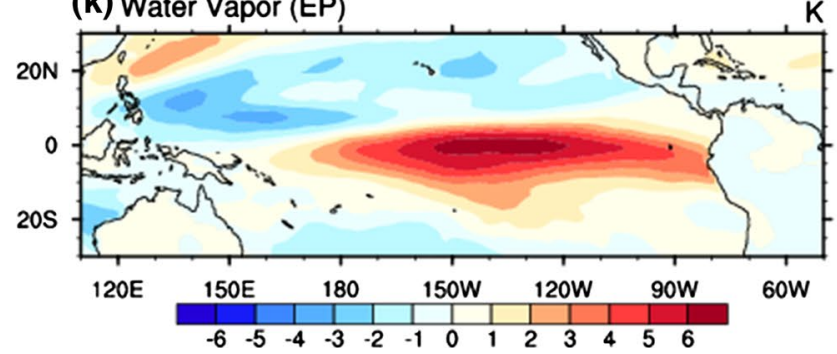

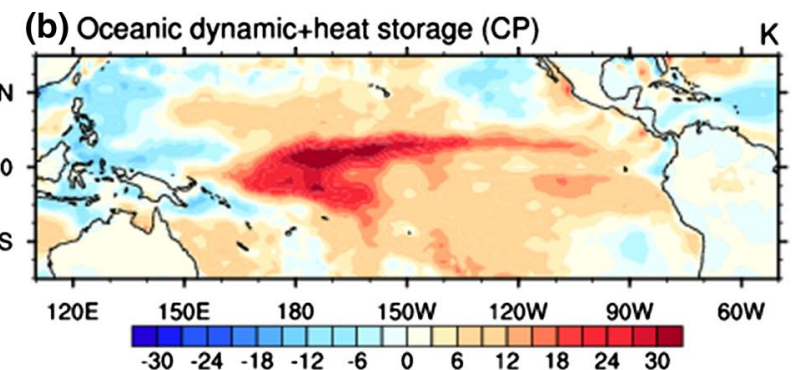

(d) Latent Heat Flux (CP)

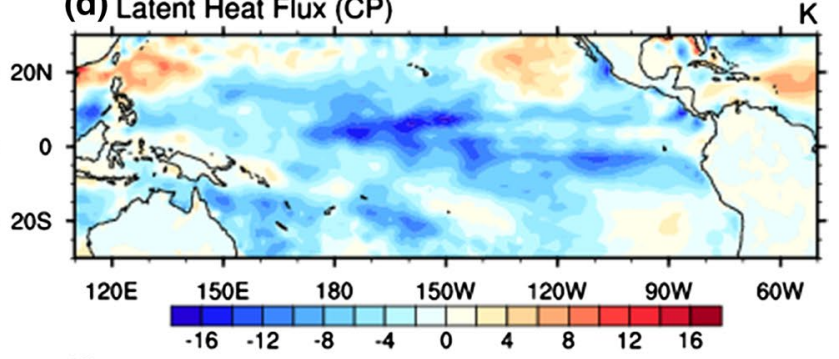

(f) Sensible Heat Flux (CP)

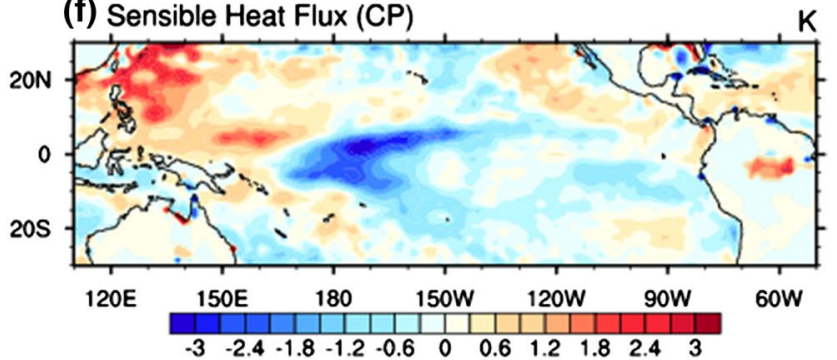

(h) Cloud (CP)
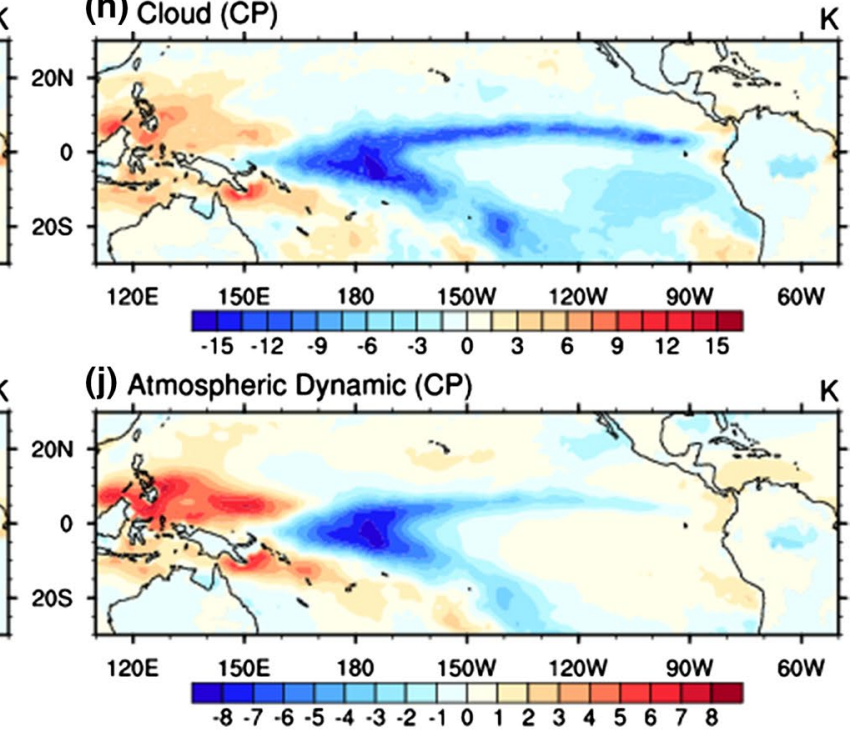

(I) Water Vapor (CP)

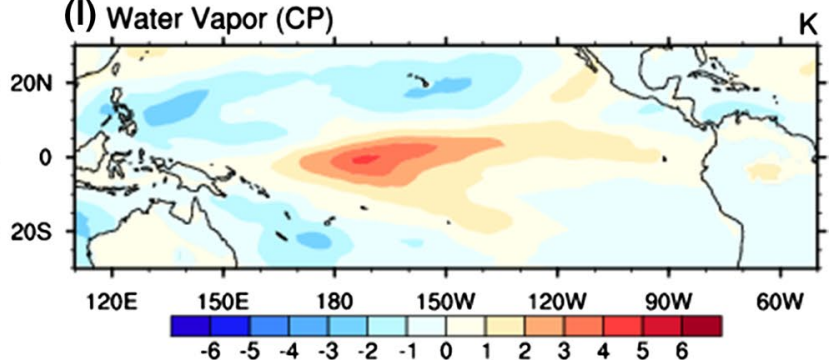


cloudiness over the central and eastern equatorial Pacific causes negative partial SST anomalies via reducing downward shortwave flux at the surface, whereas the reduction of cloudiness over the west basin results in positive SST anomalies. The spatial pattern of partial SST anomalies due to the cloud feedback closely resembles the spatial pattern due to vertical motion anomalies (Fig. 2e, f). The atmospheric dynamical feedback (Fig. 3i, j) further suppresses the SST anomalies induced by oceanic processes via a reduction of the eastward energy transport associated with a weakened Walker Circulation in El Niño winter. It is of importance to note that the suppression of oceanic processinduced SST anomalies by these four feedback processes is strongest in the region west of the central equatorial Pacific for both types of El Niño. The reduction of initial warming over the eastern basin by these processes is also similar between the two types of El Niño. Therefore, the maximum SST warming center over the eastern equatorial Pacific during the EP El Niño cannot be explained by the relatively weaker suppression of $\Delta \mathrm{T}^{(\text {ocean })}$ from these four processes.

The water-vapor feedback (Fig. 3k, 1) is the only process that acts mainly to reinforce the oceanic process-induced SST anomalies for both types of El Niño with the strongest water-vapor-induced warm SST anomalies over the central equatorial basin. The spatial pattern of $\Delta \mathrm{T}^{(\mathrm{w})}$ follows the perturbations in column-integrated water vapor closely. For the CP El Niño, the warm SST anomalies due to the watervapor feedback mainly concentrate in the central equatorial Pacific with a weaker intensity. In contrast, the warm SST anomalies due to the water-vapor feedback have a much broader pattern extending from the western equatorial basin to the eastern basin. Thus, the difference in $\Delta \mathrm{T}^{(\mathrm{w})}$ over the eastern equatorial basin between the two types El Niño is the key factor responsible for the maximum warm center of EP El Niño over the eastern equatorial basin.

\section{Zonal variation of SST anomalies in the equatorial Pacific}

To gain a better understanding of the contributions to the difference in the longitudinal distributions of SST anomalies between the two types of El Niño from individual feedback processes, we plot the longitude profiles of total (Fig. 4a) and partial (Fig. 4b-h) SST anomalies averaged over the equatorial band of $5^{\circ} \mathrm{N}-5^{\circ} \mathrm{S}$. Themaximum peak of partial SST anomalies induced by oceanic processes alone for the EP type is located about $25^{\circ}$ east of that for the CP type, although both centers are over the central equatorial Pacific (Fig. 4b). In addition, the peak of $\Delta \mathrm{T}^{\text {(ocean) }}$ of the $\mathrm{CP}$ type is narrower than that of the EP type. The combination of these characteristics of the longitudinal distributions of $\Delta \mathrm{T}^{\text {(ocean) }}$ implies that the warming of $\Delta \mathrm{T}^{\text {(ocean) }}$ on the east of the maximum $\Delta \mathrm{T}^{\text {(ocean) }}$ is stronger for the EP type than for the CP type. However, the stronger warming of $\Delta \mathrm{T}^{\text {(ocean })}$ for the EP type gradually diminishes towards the east, resulting in little difference in $\Delta \mathrm{T}^{\text {(ocean) }}$ between the two types of El Niño in the easternmost part of the equatorial Pacific. Therefore, oceanic processes alone cannot explain (1) why the maximum warming of the EP type is over the eastern basin and (2) why the warming over the eastern basin is stronger in the EP type than in the CP type.

We now examine whether the negative feedback processes that suppress the initial warming of $\Delta \mathrm{T}^{(\text {ocean })}$ would help to answer the above two questions. One can see that the profiles of $\Delta \mathrm{T}^{(\mathrm{SH})}, \Delta \mathrm{T}^{\text {(cloud) }}$, and $\Delta \mathrm{T}^{(\text {atmos) }}$ (Fig. 4f-h) are nearly parallel to those of $\Delta \mathrm{T}^{\text {(ocean) }}$, which means that the partial SST anomalies due to surface sensible heat flux, cloud and atmospheric dynamic feedbacks all act to suppress the initial warming substantially, but do not change the shape of its longitudinal distribution greatly for both types of El Niño. Therefore, these three processes could not explain the different locations of warm center between the two types of El Niño. Like these three negative feedbacks, the surface latent heat flux feedback (Fig. 4e) also acts to suppress the positive $\Delta \mathrm{T}^{\text {(ocean) }}$. For the EP type, negative $\Delta T^{(\mathrm{LH})}$ is stronger over the eastern equatorial Pacific than over the central equatorial Pacific, whereas for the CP type $\Delta \mathrm{T}^{(\mathrm{LH})}$ is stronger over the central equatorial Pacific than over the eastern equatorial Pacific (as in the other three negative feedbacks). Therefore, the surface latent heat flux feedback acts to reduce the positive $\Delta \mathrm{T}^{(\mathrm{ocean})}$ over the eastern equatorial Pacific in the EP type more effectively than in the CP type. In other words, the effect of $\Delta \mathrm{T}^{(\mathrm{LH})}$ would makes the final SST anomalies of the EP type more concentrated in the central Pacific, and thereby does not contribute to the peak warming in the eastern equatorial Pacific.

The collective effect of these four negative feedback processes is shown in Fig. 4c. We can see that the sum is nearly parallel to $\Delta \mathrm{T}^{\text {(ocean) }}$, with comparable amplitudes, implying that most of the initial warming induced by oceanic processes is nearly suppressed by these negative feedback processes, with the largest suppression over the maximum center of $\Delta \mathrm{T}^{(\text {ocean })}$ for both types of El Niño. Therefore, the negative feedback processes act to shift the maximum warming towards the eastern basin where the strength of negative feedbacks is the smallest in both types of El Niño. In this sense, the negative feedbacks contribute to the maximum warming of the EP type over the eastern basin constructively, but do not favor the maximum warming of the $\mathrm{CP}$ type over the central Pacific. Most importantly, the difference in the collective effect of these negative feedbacks between the two types of El Niño seems to imply a stronger warming over the 
(a) Total

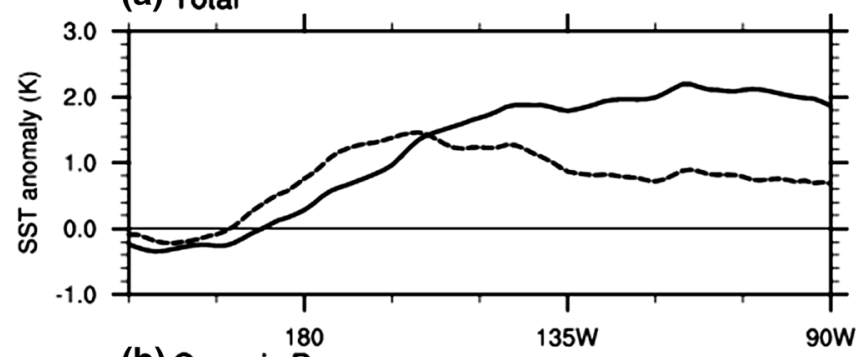

(b) Oceanic Process

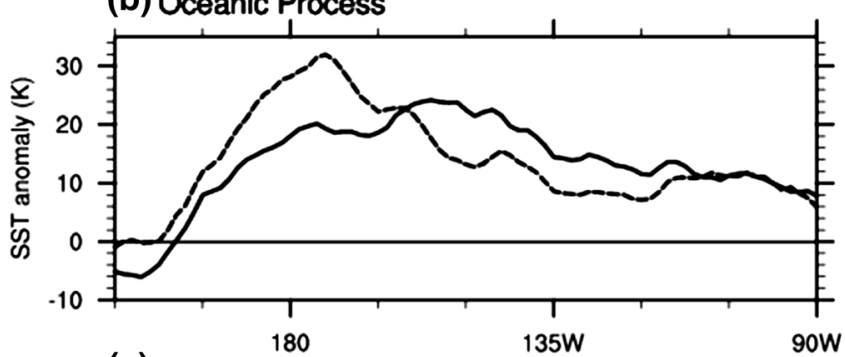

(c) Sum of (e)-(h)

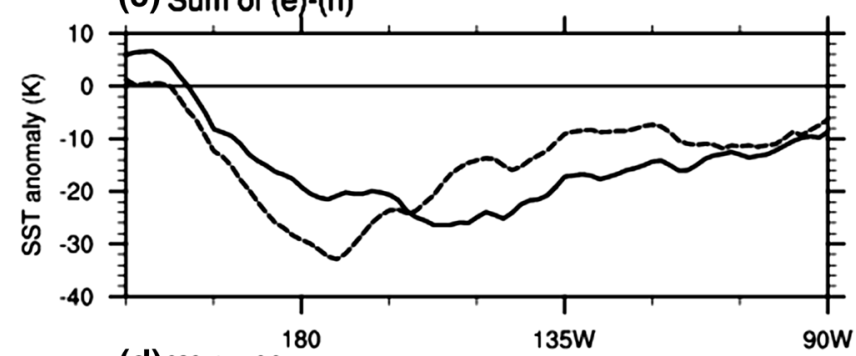

(d) Water Vapor

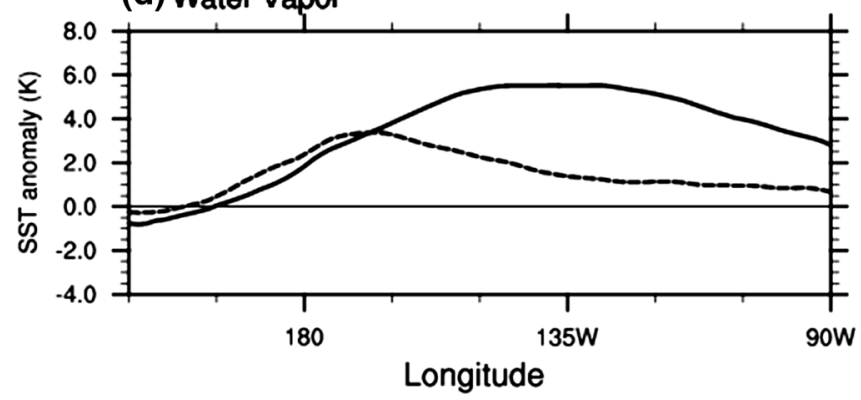

(e) Latent Heat Flux

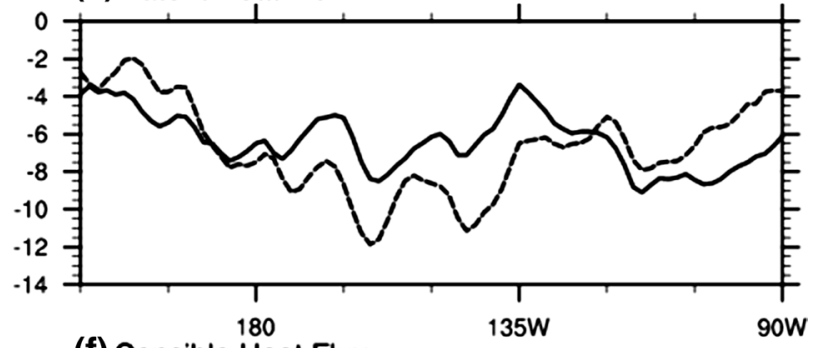

(f) Sensible Heat Flux

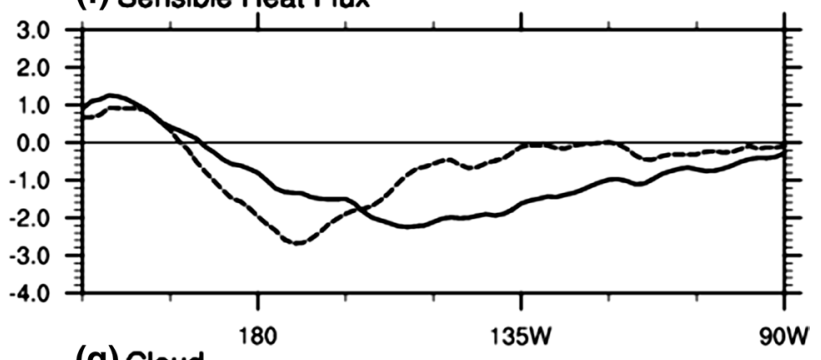

(g) Cloud

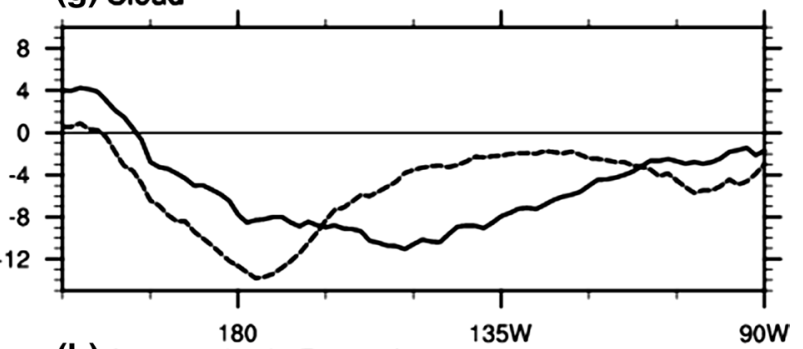

(h) Atomaspheric Dynamic

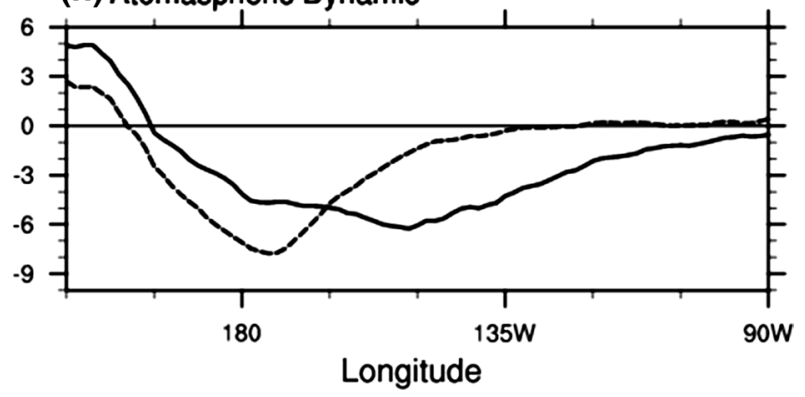

Fig. 4 Composite patterns of total surface temperature anomalies and CFRAM-derived partial surface temperature anomalies (specified in the y-coordinate) meridionally-averaged over $5^{\circ} \mathrm{N}-5^{\circ} \mathrm{S}$ for the EP (solid lines) and $\mathrm{CP}$ (dash lines) El Niño winters. Units: $\mathrm{K}$

eastern basin in the CP type rather than in the EP type, because the total negative feedback over the eastern basin is stronger in the EP type.

We now discuss the water-vapor feedback (Fig. 4d), the sole positive feedback that acts to enhance the initial warming. Because of the stronger positive $\Delta \mathrm{T}^{(\text {ocean })}$ over the eastern equatorial Pacific in the EP El Niño than in the CP El Niño (Fig. 1a vs. Figure 1b), the increase in atmospheric water vapor is stronger over the eastern equatorial Pacific in the EP case (Fig. 2a vs. b). This feature implies that the $\Delta \mathrm{T}^{(\mathrm{wv})}$ over the eastern basin is stronger in the EP type than in the CP type. Comparison of Fig. 4a-c clearly indicates that the water-vapor feedback is the sole factor that explains the feature (2) mentioned above, namely, the warming over the eastern basin is stronger in the EP type than in the CP type. Combination of the stronger negative feedback over the central equatorial Pacific and the positive water-vapor feedback also helps to explain the shift of the maximum center of the initial warming due to oceanic processes towards the eastern basin in the final warming of the EP case. In the CP case, however, the relatively weaker positive water-vapor feedback over the eastern basin (both in reference to the EP case over the eastern basin and in reference to the central Pacific) helps to maintain the maximum center in the final warming in the same region as the initial warming. 


\section{Conclusions}

Using the ERA-Interim data from 1979 to 2012, we selected four EP El Niño events, four CP El Niño events and eight neutral cases. We then used the DJF-mean differences between the four EP events and the eight neutral cases, and between the four $\mathrm{CP}$ events and the eight neutral cases, as the composite anomalies for the mature phases of EP El Niño and CP El Niño. We confirmed the following two key features in the differences of SST anomalies between the two types of El Niño reported by Larkin and Harrison (2005): (1) the maximum warming center lies over the eastern basin for the EP El Niño but over the central Pacific for the CP El Niño. (2) The warming is weaker for the CP El Niño than for the EP El Niño over most of the equatorial Pacific except for the central Pacific where the $\mathrm{CP}$ type warming is stronger.

The goal of this paper is to examine how the radiative and non-radiative thermodynamic feedbacks modify the SST anomalies induced by (air-sea coupled) oceanic dynamic processes in terms of contributing to the two key differences between the two types of El Niño. The radiative thermodynamic feedbacks include radiative flux anomalies associated with changes in water vapor, cloud and atmospheric dynamics-induced air temperature, whereas the nonradiative feedbacks include surface latent and sensible heat flux anomalies. Our attribution is complementary to the heat budget analysis based on the SST equation (e.g., Kang et al. 2001; Kug et al. 2009) where focus is placed mainly on the contributions from horizontal advective processes and upwelling/downwelling motions. Specifically, the term $\Delta \mathrm{T}^{\text {(ocean })}$ corresponds to the sum of the SST anomalies due to the ocean heat storage term and the convergence of energy transport by oceanic motions, which corresponds to the sum of all the terms in the SST equation except for the so-called residual term. Physically, the residual term in the SST equation corresponds to the SST anomalies due to air-sea coupled thermodynamic processes. In this study, our focus is on the decomposition of the contributions from these individual air-sea coupled thermodynamic processes to the SST anomalies associated with the two types of El Niño, instead of the decomposition of the SST anomalies due to the oceanic dynamic processes.

We calculated the partial SST anomalies due to oceanic processes alone and found that the oceanic process-induced SST anomalies are indeed responsible for the warming over the central and eastern equatorial Pacific and the cooling over the western basin for both types of El Niño. The longitudinal distribution (along the equatorial Pacific) of the oceanic process-induced partial SST anomalies is quite similar to that of the total SST anomalies in the CP case. However, the maximum warming due to oceanic processes in the EP case is also in the central Pacific, which is distinctly different from the location of the total SST anomalies. Therefore, it has to be the combination of stronger positive feedbacks over the eastern equatorial Pacific and stronger negative feedbacks over the central equatorial Pacific in the EP case than in the $\mathrm{CP}$ case that can explain the two key features in the differences between the two types of El Niño.

Except for the water-vapor feedback, all other four feedback processes (surface latent heat flux, surface sensible heat flux, cloud, and atmospheric dynamic feedbacks) act to oppose the initial warming due to oceanic processes. Overall, there is no drastic difference in the anomaly fields of these four feedback processes between the two types of El Niño, except that the maximum center is displayed slightly eastward in the EP case. In both types of El Niño, surface latent heat flux increases over the region from the central Pacific to the eastern Pacific along the equator and so does surface sensible heat flux. As a result, these two processes act to weaken the initial warming due to oceanic processes substantially, with the maximum warming reduction over the central Pacific in both cases. There are upward vertical motion anomalies over the central Pacific where the maximum warming center appears due to oceanic processes and downward vertical motions over the western basin where the oceanic processes cause cold SST anomalies. This feature is indicative of a weakening of the Walker Circulation, responsible for the reduction of the initial warming in the central Pacific and for the initial cooling in the western basin via atmospheric dynamic feedback processes. Coinciding with the upward (downward) vertical motion anomalies, positive (negative) cloud anomalies lead to further reduction of the initial warming (cooling) via a decrease (an increase) in solar energy input at the sea surface over the central (western) Pacific. The general similarity in these four negative feedback processes between the two types of El Niño implies that the negative feedback processes cannot explain the contrast of the SST anomalies, although they do act to suppress the initial warming due to oceanic processes by contributing to the warming in the atmosphere.

The water-vapor feedback is the only process that acts to enhance the initial warming. The larger increase in atmospheric water vapor leads to a stronger water-vapor feedback over the eastern basin in the EP El Niño than in the CP El Niño. Therefore, the water-vapor feedback is the sole factor that can explain why the warming over the eastern basin is stronger in the EP El Niño. This factor and the stronger negative feedbacks over the central equatorial Pacific explain why the maximum warming for the EP case is over the eastern basin.

Acknowledgments We are grateful to the Editor, Prof. Jianping Li, and the two anonymous reviewers whose thoughtful and informative 
comments have led to a significant improvement in the presentation and readability of the paper. The study was supported by the National Key Research Program of China (Grants 2014CB953904 and 2012CB956002), the National Natural Science Foundation of China (Grant 41375081), the China Special Fund for Meteorological Research in the Public Interest (No. GYHY201406018), the LASW State Key Laboratory Special Fund (2013LASW_A05), the Jiangsu Collaborative Innovation Center for Climate Change, and the Zhuhai Joint Innovative Center for Climate, Environment and Ecosystem. This study was also supported by the International Program for Ph.D. Candidates of Sun Yat-sen University. Ming Cai was supported by a grant from the National Science Foundation of the US (AGS-1354834). The ERA Interim data used in this study were provided by the European Centre for Medium-range Weather Forecasts (ECMWF). Calculations used in this study were carried out on the High-Performance Grid Computing Platform of Sun Yat-sen University and the China National Supercomputer Center in Guangzhou.

Open Access This article is distributed under the terms of the Creative Commons Attribution 4.0 International License (http://creativecommons.org/licenses/by/4.0/), which permits unrestricted use, distribution, and reproduction in any medium, provided you give appropriate credit to the original author(s) and the source, provide a link to the Creative Commons license, and indicate if changes were made.

\section{References}

Ashok K, Behera SK, Rao SA, Weng H, Yamagata T (2007) El Niño Modoki and its possible teleconnection. J Geophys Res 112:C11007. doi:10.1029/2006JC003798

Bjerknes J (1969) Atmospheric teleconnections from the equatorial Pacific. Mon Weather Rev 97:163-172

Cai M, Lu J-H (2009) A new framework for isolation individual feedback processes in coupled general circulation climate models. Part II: method demonstrations and comparisons. Clim Dyn 32:887-900. doi:10.1007/s00382-008-0424-4

Cai M, Tung K-K (2012) Robustness of dynamical feedbacks from radiative forcing: $2 \%$ solar versus $2 \times \mathrm{CO}_{2}$ experiments in an idealized GCM. J Atmos Sci 69:2256-2271

Capotondi A (2013) ENSO diversity in the NCAR CCSM4 climate model. J Geophys Res Oceans 118:4755-4770

Capotondi A, Wittenberg AT, Newman M, Lorenzo ED, Yu J-Y, Braconnot P, Cole J, Dewitte B, Giese B, Guilyardi E, Jin FF, Karnauskas K, Kirtman B, Lee T, Schneider N, Xue Y, Yeh SW (2015) Understanding ENSO diversity. Bull Am Meteorol Soc. doi:10.1175/BAMS-D-13-00117.1

Chandra S, Ziemke JR, Min W, Read WG (1998) Effects of 1997 1998 El Niño on tropospheric ozone and water vapor. Geophys Res Lett 25(20):3867-3870

Chandra S, Ziemke JR, Schoeber MR, Froidevaux L, Read WG, Levelt PF, Bhartia PK (2007) Effects of the 2004 El Niño on tropospheric ozone and water vapor. Geophys Res Lett 34:L06802. doi:10.1029/2006GL028779

Chung P-H, Li T (2013) Interdecadal relationship between the mean state and El Niño types. J Clim 26:361-379. doi:10.1175/ JCLI-D-12-00106.1

Dee DP, Uppala SM, Simmons AJ, Berrisford P, Poli P, Kobayashi S, Andrae U, Balmaseda MA, Balsamo G et al (2011) The ERAinterim reanalysis: configuration and performance of the data assimilation system. Q J R Meteorol Soc 137:553-597
Deng Y, Park T-W, Cai M (2012) Process-based decomposition of the global surface temperature response to El Niño in boreal winter. J Atmos Sci 69:1706-1712

Deng Y, Park T-W, Cai M (2013) Radiative and dynamical forcing of the surface and atmospheric temperature anomalies associated with the northern annular mode. J Clim 26:5124-5138

Dessler AE, Wong S (2009) Estimates of the water vapor climate feedback during El Niño-Southern oscillation. J Clim 22:6404-6412

Hirst AC (1986) Unstable and damped equatorial models in simple coupled ocean-atmosphere models. J Atmos Sci 43:606-630

Jin F-F (1997a) An equatorial ocean recharge paradigm for ENSO. Part I: conceptual model. J Atmos Sci 54:811-829

Jin F-F (1997b) An equatorial ocean recharge paradigm for ENSO. Part II: a stripped-down coupled model. J Atmos Sci 54:830-847

Jin F-F, An SI (1999) Thermocline and zonal advective feedbacks within the equatorial ocean recharge oscillator model for ENSO. Geophys Res Lett 26:2989-2992

Kang IS, An SI, Jin F-F (2001) A systematic approximation of the SST anomaly equation for ENSO. J Meteorol Soc Japan 79:1-10

Kao HY, Yu J-Y (2009) Contrasting eastern-Pacific and central-Pacific types of ENSO. J Clim 22:615-632

Kug JS, Jin F-F, An SI (2009) Two types of El Niño events: cold tongue El Niño and warm pool El Niño. J Clim 22:1499-1515

Kug JS, Choi J, An SI, Jin F-F, Wittenberg AT (2010) Warm pool and cold tongue El Niño events as simulated by the GFDL 2.1 coupled GCM. J Clim 23:1226-1239

Larkin NK, Harrison DE (2005) On the definition of El Niño and associated seasonal average US weather anomalies. Geophys Res Lett 32:L13705. doi:10.1029/2005GL022738

Lau K-M, Yang S (2002) Walker circulation. Encyclopedia of Atmospheric Sciences, San Diego

Lee T, McPhaden MJ (2010) Increasing intensity of El Niño in the central-equatorial Pacific. Geophys Res Lett 37:L14603. doi:10.1029/2010GL044007

Lloyd J, Guilyardi E, Weller H (2011) The role of atmosphere feedbacks during ENSO in the CMIP3 models. Part II: using AMIP runs to understand the heat flux feedback mechanisms. Clim Dyn 37:1271-1292

Lloyd J, Guilyardi E, Weller H (2012) The role of atmosphere feedbacks during ENSO in the CMIP3 models. Part III: the shortwave flux feedback. J Clim 25:4275-4293

Lu J-H, Cai M (2009) A new framework for isolating individual feedback processes in coupled general circulation climate models.Part I: formulation. Clim Dyn 32:873-885. doi:10.1007/ s00382-008-0425-3

Lu J-H, Cai M (2010) Quantifying contributions to polar warming amplification in an idealized coupled general circulation model. Clim Dyn 34:669-687

Lübbecke JF, McPhaden MJ (2014) Assessing the twenty-first-century shift in ENSO variability in terms of the Bjerknes stability index. J Clim 27:2577-2587

Nagai T, Tokioka T, Endoh M, Kitamura Y (1992) El Niño-Southern Oscillation simulated in an MRI atmosphere-ocean coupled general circulation model. J Clim 5:1202-1233

Neelin JD, Battisti DS, Hirst AC, Jin F-F, Wakata Y, Yamagata T, Zebiak SE (1998) ENSO theory. J Geophys Res 103:1426114290. doi: $10.1029 / 97 J C 03424$

Park T-W, Deng Y, Cai M (2012) Feedback attribution of the El NiñoSouthern Oscillation-related atmospheric and surface temperature anomalies. J Geophys Res 117:D23101. doi:10.1029/201 2JD018468

Park T-W, Deng Y, Cai M, Jeong J-H, Zhou R (2013) A dissection of the surface temperature biases in the Community Earth System Model. Clim Dyn 43:2043-2059 
Picaut J, Masia F, Penhoat Y (1997) An advective-reflective conceptual model for the oscillatory nature of the ENSO. Science 277:663-666

Rasmusson EM, Carpenter TH (1982) Variations in tropical sea surface temperature and surface wind fields associated with the Southern Oscillation/El Niño. Mon Weather Rev 110:354-384

Schneider EK, Huang B, Shukla J (1995) Ocean wave dynamics and El Niño. J Clim 8:2415-2439

Sejas SA, Cai M, Hu A-X, Meehl GA, Washington W, Taylor PC (2014) Individual feedback contributions to the seasonality of surface warming. J Clim 27:5653-5669

Suarez MJ, Schopf PS (1988) A delayed action oscillator for ENSO. J Atmos Sci 45:3283-3287

Sun F-P, Yu J-Y (2009) A 10-15-Yr Modulation Cycle of ENSO Intensity. J Clim 22:1718-1735

Takahashi H, Su H, Jiang J-H, Luo Z-J, Xie S-P, Hafner J (2013) Tropical water vapor variations during the 2006-2007 and 20092010 El Niños: satellite observation and GFDL AM2.1 simulation. J Geophys Res Atmos 118:8910-8920

Uppala SM, Dee D, Kobayashi S, Berrisford P, Simmons A (2008) Towards a climate 500 data-assimilation system: status update of ERA-Interim. ECMWF Newslett 115:12-18

Vimont DJ, Battisti D, Hirst A (2001) Foot printing: a seasonal connection between the tropics and mid-latitudes. Geophys Res Lett 28:3923-3926

Vimont DJ, Wallace JM, Battisti DS (2003) The seasonal foot printing mechanism in the Pacific: implications for ENSO. J Clim $16: 2668-2675$

Vimont DJ, Alexander M, Fontaine A (2009) Midlatitude excitation of tropical variability in the Pacific: the role of thermodynamic coupling and seasonality. J Clim 22:518-534

Wakata Y, Sarachik ES (1991) Unstable coupled atmosphere-ocean basin modes in the presence of a spatially varying basic state. $\mathrm{J}$ Atmos Sci 48:2060-2077

Wang C, Wang X (2013) Classifying El Niño Modoki I and II by different impacts on rainfall in southern China and typhoon tracks. J Clim 26:1322-1338
Xie F, Li J, Tian W, Huo Y (2012) Signals of El Niño Modoki in the tropical tropopause layer and stratosphere. Atmos Chem Phys 12:5259-5273

Xie F, Li J-P, Tian WS, Zhang J-K, Shu J-C (2014) The impacts of two types of El Niño on global ozone variations in the last three decades. Adv Atmos Sci 31:1113-1126. doi:10.1007/ s00376-013-3166-0

Yang Y, Ren R, Cai M, Rao J (2014) Attributing analysis on the model bias in surface temperature in the Climate System Model FGOALS-s2 through a process-based decomposition method. Adv Atmos Sci. doi:10.1007/s00376-014-4061-z

Yeh S-W, Kug J-S, Dewitte B, Kwon M-H, Kirtman BP, Jin F-F (2009) El Niño in a changing climate. Nature 461:511-514

Yu J-Y, Kao H-Y (2007) Decadal changes of ENSO persistence barrier in SST and ocean heat content indices: 1958-2001. J Geophys Res 112:D13106. doi:10.1029/2006JD007654

Yu J-Y, Kao H-Y, Lee T (2010) Subtropics-related interannual sea surface temperature variability in the equatorial Central Pacific. J Clim 23:2869-2884

Yu J-Y, Zou Y, Kim S-T, Lee T (2012) The changing impact of El Niño on US winter temperatures. Geophys Res Lett 39:L15702. doi:10.1029/2012GL052483

Yu J-Y, Wang X, Yang S, Paek H, Chen M (2015) The changing El Niño Southern Oscillation. In: Wang S-Y, Yoon J-H, Funk C, Gillies RR (eds) Climate Extremes: patterns and mechanisms. AGU Monograph (accepted)

Yuan Y, Yang S (2012) Impacts of different types of El Niño on the East Asian climate: focus on ENSO cycles. J Clim 25:7702-7722

Yuan Y, Yang S, Zhang Z (2012) Different evolutions of the Philippine Sea anticyclone between eastern and central Pacific El Niño: possible effect of Indian Ocean SST. J Clim 25:7867-7883

Zheng F, Fang X-H, Yu J-Y, Zhu J (2014) Asymmetry of the Bjerknes positive feedback between the two types of El Niño. Geophys Res Lett 41:7651-7657 